\title{
DEL SENTIDO DE LA REALIDAD \\ A LA REALIDAD DEL SENTIDO. EL HABER COMO CENTRO COMÚN A HEIDEGGER Y ZUBIRI
}

\author{
JOSÉ M MáMEZ DELGADO
}

Universidad de Granada

\begin{abstract}
RESUMEN: El objetivo de este artículo es ilustrar las condiciones para una transformación zubiriana de la hermenéutica. El primer paso consiste en la hipótesis acerca de la posibilidad de hallar un núcleo de pensamiento común a Heidegger y Zubiri. El autor adopta la estrategia de analizar las razones que están detrás del rechazo heideggeriano del concepto de realidad y del rechazo zubiriano del concepto de sentido (en un nivel originario). Luego, muestra la posibilidad de hallar en la filosofía de Heidegger algunas dimensiones que se sitúan más allá del sentido y de la Bedeutsamkeit. En este punto, nos sale al encuentro el concepto de «haber» relacionado con la expresión heideggeriana "es gibt»y con el concepto de Ereignis. Finalmente, el autor asevera que el centro común yace en el sentido prefilosófico de la palabra ousía, presente tanto en Heidegger como en Zubiri. En semejante empleo de ousía, el autor ve la intención de pensar la propiedad de la cosa, su pertenencia a sí misma. De ahí que el concepto de pertenencia se convierta en la clave para vincular la expresión «de suyo» con el concepto de Ereignis. Una clave que permite traducir la pregunta hermenéutica en estos términos: «¿Qué es el sentido desde su realidad física?».
\end{abstract}

PALABRAS CLAVE: haber, Ereignis, ousía, hermenéutica, suidad.

\section{From the sense of reality to the reality of sense. Haber as a common core to Heidegger and Zubiri}

\begin{abstract}
The aim of this article is to illustrate the conditions for a zubirian transformation of Hermeneutics. The first step is the hypothesis about the possibility of finding a common core of thought to Heidegger and Zubiri. The author adopts the strategy of analyzing the reasons which are behind the heideggerian refusal of the concept of reality and behind the zubirian refusal of the concept of sense (at an original level). Then, He shows the possibility of finding in Heidegger's philosophy some dimensions which are situated over the sense and the Bedeutsamkeit. At this stage, the concept of "haber" comes up related to the heideggerian expression "es gibt" and to the concept of Ereignis. At the end, the author argues that the common core lies in the prephilosophical sense of the word ousia, which is present both in Heidegger and in Zubiri. In this use of ousia, the author sees the intention of thinking the thing's property, it's belonging to itself. So, the concept of belonging becomes the key which links the expression "de suyo" to the concept of Ereignis. A key which permits to translate the hermeneutical question in these words: "What is sense from its physical reality?».
\end{abstract}

KEY WORDS: haber, Ereignis, ousía, Hermeneutics, suidad. 


\section{Del giro metafísico a UnA transformación FENOMENOOLÓGICA ${ }^{1}$ DE LA HERMENÉUTICA}

El título de este trabajo puede evocar, a su manera, el giro metafísico a que hiciera referencia P. Cerezo en su lectura de la filosofía de Zubiri vertida en «Del sentido a la realidad», donde destacaba cómo frente a otros giros, tales como el antropológico y el lingüístico, el de Zubiri lo sería de vuelta a la metafísica ${ }^{2}$. Otro de los referentes de este giro se encuentra, sin lugar a dudas, en lo hermenéutico; esto es, frente a la fenomenología hermenéutica que delinea su ámbito específico a través de categorías ligadas a la historicidad, tales como la vida fáctica o Dasein, la temporeidad y el sentido y la significatividad. Es por ello que algunos como J. A. Nicolás y J. Conill han hablado no de giro sino de transformación a la hora de tomar esta disensión zubiriana con respecto a Heidegger como punto de partida de un programa de complementación de la hermenéutica a través de una noción de razón experiencial ${ }^{3}$. Este interés es el que vamos a tomar como meta a larga distancia del estudio de la relación Heidegger-Zubiri.

Ahora bien, si de giro o transformación se quiere hablar, este transcurso deberá tener acaso un sustrato común, un punto compartido tanto por uno como otro. Es por ello que en este trabajo nos fijaremos en un objetivo más

1 Listado de abreviaturas en este trabajo. Obras de Heidegger: GA (Gesamtausgabe. Frankfurt: Vittorio Klostermann, 1976-. En el caso de no indicar traductor, la traducción será propia), SZ (Sein und Zeit (1927). Tübingen: Max Niemeyer, 2006, cuyos textos citados son traducidos según Ser y tiempo, trad. de J. E. Rivera. Madrid: Trotta, 2003). Fuentes de Zubiri: CU-I (Cursos Universitarios, I. Madrid: Alianza, 2007), CU-II (Cursos Universitarios, II. Madrid: Alianza, 2010), CU-III (Cursos Universitarios, III. Madrid: Alianza, 2012), NHD (Naturaleza, historia, Dios (1944). Madrid: Alianza, 2007), SPF (Sobre el problema de la filosofía. Madrid: Alianza, 2002); SE (Sobre la esencia (1962). Madrid: Alianza, 1985), HV (El hombre y la verdad. Madrid: Alianza, 1999), SH (Sobre el hombre. Madrid: Alianza, 1986), SR (Sobre la realidad. Madrid: Alianza, 2001), SSV (Sobre el sentimiento y la volición. Madrid: Alianza, 1992), EDR (Estructura dinámica de la realidad. Madrid: Alianza, 1989), AM (Acerca del mundo. Madrid: Alianza, 2010), IRE (Inteligencia y realidad (1980). Madrid: Alianza, 2006), IL (Inteligencia y logos. Madrid: Alianza, 1982), HD (El hombre y Dios (1984). Madrid: Alianza, 2012), AXZ (Archivo Xavier Zubiri, en la Fundación Xavier Zubiri, Madrid).

En lo sucesivo emplearemos el término «fenomenoología» para hacer referencia al planteamiento noológico de Zubiri que atiende a análisis de hechos de experiencia (desde la consideración de la intelección sentiente), y que queremos poner expresamente en continuidad con una tradición fenomenológica que, sin ceñirse a las versiones de la fenomenología en Husserl o en Heidegger, arranca de ellas y supone una nueva versión, en la que la noción de intencionalidad queda conceptuada como noergia o intencionalidad física.

2 Vid. Cerezo, P., «Del sentido a la realidad. El giro metafísico en X. Zubiri», en VV.AA., Del sentido a la realidad. Estudios sobre la filosofía de Zubiri. Madrid: Trotta, 1995, p. 226.

3 Vid. Conill, J., El enigma del animal fantástico. Madrid: Tecnos, 1991, p.163; «Concepciones de la experiencia», en Diálogo Filosófico, n41 (1998), p. 150; «La verdad de la razón experiencial», en Nicolás, J. A. / Frápolli, M. J., Verdad y experiencia. Granada: Comares, 1999, p. 188; Nicolás, J. A., «La transformación de la hermenéutica», en Murillo, I. (ed.), Fronteras de la filosofía. Madrid: Diálogo filosófico, 2000, pp. 439-448. 
inmediato, que atañe a la búsqueda de un sustrato común y nos permitiera transitar efectivamente desde una filosofía a la otra. Nuestra propuesta sería entonces examinar las implicaciones filosóficas entre sentido y realidad respectivamente para encontrar un centro común a ambas posturas en el cual pudieran coincidir y que, en una instancia ulterior, ejerciera de apoyo filosófico para un programa de transformación zubiriana de la hermenéutica.

¿Dónde y cómo buscar estos elementos comunes? A la hora de investigar la relación entre ambos se han solido adoptar al menos tres enfoques diferentes en función de la época de Heidegger tomada como objeto de interlocución de la filosofía de Zubiri en general: (1) Zubiri con el Heidegger de Sein und Zeit proyectado hacia delante (i.e. obras de la Kehre), (2) Zubiri con el Heidegger de la Kehre (tomando el pensar del Ereignis como clave fundamental) y (3) Zubiri con el Heidegger de Sein und Zeit proyectado hacia atrás (esto es, el Heidegger de las lecciones de los años veinte: de las frühe Freiburger y las Marburger Vorlesungen). La inmensa mayoría de trabajos sobre el tema Zubiri-Heidegger se han centrado por lo general en los dos primeros enfoques ${ }^{4}$, mientras que el último ha sido menos atendido ${ }^{5}$. Sin ir más lejos, las diversas propuestas de acercamiento entre ambos autores se han movido dentro del segundo enfoque. Es el caso de A. GonZález ${ }^{6}$, quien ha planteado una correlación entre el Ereignis del último Heidegger y la verdad real junto con el «de suyo» de Zubiri. En esta misma línea R. EsPinoza ha llegado a mantener que «es posible pensar a Zubiri y a Heidegger desde un centro común que les permita dialogar en lo esencial, pero esto solamente es posible después de Sein und Zeit ${ }^{7}$, centro común que estaría en el «de suyo» pero que, sin embargo, «no tenía ninguna razón de ser en 1927, en Sein und Zeit...».

Sin embargo, el tercer enfoque, el concerniente al Heidegger de los años veinte, podría arrojar resultados igualmente provechosos para el hallazgo de esos centros comunes, pues fue aquel en buena medida el que conoció de primera mano Zubiri durante su estancia en Freiburg entre 1928 y 1930. La crítica a Heidegger vertida en sus obras tiene en cuenta, como es notorio, escritos de la Kehre, pero también algún curso de las lecciones de los años veinte (en especial, el del SS 1927 Die Grundprobleme der Phänomenologie) y, sobre todo, Sein und Zeit. Esto produce que su interpretación del pensamiento de Heidegger

4 Como ejemplos del primer enfoque vid. p.e. Gracia, D., «El problema del fundamento", en Nicolás, J. A. / Espinoza, R., Zubiri ante Heidegger. Barcelona: Herder, 2008, pp. 33-79; GonZÁlez, A., «Las cosas», en op. cit., pp. 107-136; DANEL, F., «El poder y el poderío: la noergia de Zubiri frente a Heidegger», en op. cit., pp. 385-467; GonZÁLEZ, A., «Las cosas», en op. cit., pp. 107-136.

5 No obstante vid. el ejemplar estudio en esta línea de GonzÁLEz, A., «El eslabón aristotélico», en Cuadernos Salmantinos de Filosofía, xxxv (2008), pp. 5-36.

6 Vid. González, A., «Ereignis y actualidad», en Gracia, D., Desde Zubiri. Granada: Comares, 2004, pp. 103-192.

7 Espinoza, R., «Zubiri y Sein und Zeit», en Nicolás, J. A., Guía Comares de Zubiri. Granada: Comares, 2011, p. 212.

8 Espinoza, R., Realidad y ser en Zubiri. Granada: Comares, 2013, p. 10. 
se concentre con mayor intensidad en la asimilación de la obra del 27 que en preguntarse qué supone la perspectiva de la Kehre para aquella. Al señalar tales datos no pretendemos en absoluto tachar de erróneos el primer y el segundo enfoque, sino, simplemente, reclamar la importancia del tercer enfoque como un filón aún por explotar en el estudio de la relación Zubiri-Heidegger. En ese sentido podemos preguntarnos, a modo de hipótesis, si podría encontrarse un centro común en algún elemento de ambas filosofías que permita pensar el «de suyo» desde y antes de Sein und Zeit.

A tales efectos vamos a adoptar la siguiente estrategia: en un primer paso comenzaremos por examinar las razones del rechazo, en el caso de Heidegger, de la realidad y, en el de Zubiri, del sentido como categorías para pensar las cosas mismas. Aprovecharemos en este punto para valorar las tesis de cada uno desde el punto de vista del otro, y, en el caso de Zubiri, a matizar un aspecto de su crítica a la fenomenología hermenéutica. Ahora bien, en un segundo paso, vamos a tratar de mostrar cómo las razones de este rechazo no sólo les conducen a un terreno en común, sino que además propician la aparición de un término que da expresión a este encuentro implícito de sus filosofías. Dicho término, como veremos, será el de haber.

\section{SENTIDo y REALIDAD EN DISPUTA}

El comienzo de esta búsqueda puede ubicarse en un punto inicial en el que, sin embargo, se encuentra implícitamente una clara desavenencia. Este tiene que ver con un tema central de la filosofía, el de la verdad, en el que tanto Heidegger como Zubiri coinciden a la hora de ubicarlo en un nivel ante-predicativo y pre-posicional, para lo cual apelan a la aỉ $\sigma \theta \eta \sigma r \varsigma$ aristotélica como su lugar propio. Por un lado, en el §7(b) de Sein und Zeit se llama la atención sobre el tipo de verdad propio de la simple percepción sensible de algo como un puro vozĩv que jamás puede ser falso (SZ, 33); mientras que, por su parte, Zubiri sigue en paralelo este rastro aristotélico cuando hacia el final de "¿Qué es saber?» (1935) recupera la idea del voũ s como un palpar o tantear (NHD, 80) en compenetración con la impresión sensible (NHD, 85; vid. también CU-I, $188,191,289,293,314)$.

Ello da cuenta de cómo ambos sitúan en la experiencia la verdad del saber. Ahora bien, mientras que a Zubiri la atención a la experiencia le conducirá a la elaboración de la idea de impresión de realidad como instancia donde tiene lugar esa verdad, a Heidegger le conducirá más bien a formular su postura a través de la idea de intuición hermenéutica y, posteriormente, de comprensióninterpretación ${ }^{9}$. Mismo comienzo experiencial, pero divergentes concepciones

9 Es posible seguir el rastro histórico-genético de este desarrollo si atendemos a cómo Heidegger arranca no sólo de Husserl sino también de E. Lask (y su principio de determinación material de la forma) para llegar a la idea de una intuición hermenéutica, esto es, 
de la experiencia parecen consistir en uno de los motivos iniciales que propician un ulterior desacuerdo entre ambos. Sin ir más lejos, ¿qué tendría que decir la fenomenología hermenéutica de la descripción zubiriana de la experiencia? ¿Y viceversa? ¿Cómo se considera desde una y otra postura el contenido y carácter de la experiencia?

\subsection{El sentido de la realidad: Zubiri desde el Heidegger de los años veinte}

En sus descripciones fenomenoológicas Zubiri nos habla de experiencias como ver una copa de vino (NHD, 61), padecer una enfermedad (NHD, 63-4), ver este vaso de agua (HV, 29), un color verde (IRE, 258), sentir algo caliente (IRE, 172-3, 83), contemplar un paisaje (IRE, 257), aprehender una constelación de notas como peso, color, forma, etc. (IRE, 59) en contraposición a otras cosas como una mesa o la hacienda agraria (SE, 104-5). Sobrevolando estas descripciones gravita una de las tesis fundamentales de (prácticamente) todo Zubiri: la distinción entre cosa-real y cosas-sentido. Mesa y hacienda agraria pertenecerían a estas últimas, que son asociadas expresamente al concepto de experiencia en Heidegger. La concesión, por lo tanto, de prioridad a las llamadas cosas reales tiene que ver con la preeminencia en la experiencia de caracteres propiamente sensibles (peso, forma, color, etc.).

¿Qué tendría que decir Heidegger de estas descripciones? Ya desde la primera de las lecciones tempranas de Friburgo deja muy clara su oposición a una concepción de la experiencia desde las cualidades sensibles. En la célebre descripción de la vivencia de la cátedra en el curso del KNS 1919 Heidegger pregunta a sus alumnos qué ven exactamente al entrar a la clase: ¿Líneas y formas? ¿Una caja marrón? O, como podría haber respondido algún hipotético alumno zubiriano en aquella aula de 1919: ¿algo con un peso, forma, color, etc.? El profesor Heidegger hubiera reprendido inmediatamente a nuestro inaprensivo zubiriano y le hubiese invitado a caer en la cuenta de que nuestra primera relación con el mundo es de tipo pragmático: veo la cátedra desde la que el profesor me habla (cf. GA 56/57, 70-71). En este punto el carácter significativo con que comparece el mundo (Bedeutsamkeit) desplazaría al ver perceptivo de cualidades sensibles de los objetos.

Quizás el empecinado zubiriano hubiese replicado, haciendo el silencio en clase, que a pesar de todo la sensibilidad debería jugar algún papel en el entramado de la experiencia. Heidegger hubiese torcido el gesto a la par que admitiera que, evidentemente «veo algo marrón, el color marrón. Pero no lo veo como sensación-marrón, como un momento de mis procesos psíquicos. Veo algo marrón, pero en una conexión significativa unitaria con la cátedra» (GA 56/57, 85). La sensibilidad no puede estar ausente del mundo de la vivencia;

significativa; mientras que Zubiri, que tiene una fuente remota pareja en Husserl, va haciendo su camino a través del realismo inmediato y de la intuición sensible-intelectual de L. Nöel, para llegar finalmente a la idea de la impresión de realidad. Evidentemente, aquí no podemos detenernos en la reconstrucción de este proceso de desarrollo filosófico. 
lo que Heidegger quiere excluir expresamente es que ésta tenga función directriz o fundamentadora alguna (cf. GA 56/57, 71). Su tesis consiste en que la apertura significativa al mundo supone el desplazamiento de la sensibilidad, no su eliminación total. Es posible que el profesor Heidegger acabara acorralando a nuestro zubiriano acusándolo de adoptar una actitud muy artificiosa cuando se refiere a contenidos tales como peso, forma, color, etc. y, además, los toma como rectores de la apertura al mundo. Sería ahora ese alumno zubiriano sospechoso de comportarse de una manera a-fenomenológica, adoptando una actitud teorética (theoretische Einstellung), que acabaría suponiendo a la postre una desvivificación de la experiencia (Entlebung), una cosificación que destruye la efectividad experiencial con la que se dan las cosas en la facticidad (cf. GA 56/57, 73-74).

Ahora bien, tras acabar la clase nuestro atribulado zubiriano marcharía hacia casa rumiando las razones de esta áspera desavenencia, donde, al examinar su bibliografía, encontraría que entre los libros de actualidad (en 1919) los neokantianos y husserlianos podrían explicar en buena medida la motivación de Heidegger a la hora de rechazar el ver perceptivo y asociarlo a una actitud teorética. En las lecciones tempranas de Friburgo y las de Marburgo los alumnos de Heidegger habrán comprendido cómo desde el punto de vista de la experiencia de la vida fáctica las posturas neokantianas y husserlianas deberían ser tildadas de epistemologicistas. Frente al esquema abstracto de la experiencia en el neokantismo (que separa sensibilidad, entendimiento y razón) y frente a la reducción eidética del mundo en Husserl, las lecciones de los años veinte de Heidegger reclaman a sus alumnos devolver la cuestión filosófica central a mostrar «la motivación del sentido de la realidad (como momento de sentido teorético) a partir de la inmediata vivencia del mundo circundante» (GA 56/57, 92); esto es, a mostrar cómo, más bien, la cuestión de la realidad de nuestras percepciones sensibles sólo tiene lugar sobre un horizonte previo que corresponde a la apertura significativa en la vivencia de un mundo circundante.

Tras denodados años de estudio del pensamiento heideggeriano entre 19191927 a aquel zubiriano no le quedaría más remedio que comprender, al tomar finalmente entre sus manos en 1927 Sein und Zeit, que aquel concepto por el que bregaba frente a Heidegger, la realidad, cae finalmente bajo la consideración de un mero modo de ser. Probablemente el zubiriano prestaría atención y trabajaría con intensidad el parágrafo 43 , como realmente hizo el propio Zubiri con su ejemplar de SZ - cuyo pasaje correspondiente aparece copiosamente subrayado y anotado-, dedicado a analizar el concepto de Realität. Quizás podría guardarse una pregunta para Heidegger, a la espera de alguna oportunidad que tuviera en Freiburg, y plantearle si acaso al rechazar la realidad como concepto adecuado para pensar las cosas mismas no estaría perdiendo una buena oportunidad para dar cumplimiento al objetivo prioritario de Sein und Zeit, a saber: responder a la pregunta por el ser del ente en general (ïberhaupt), no sólo del que tiene el modo de ser de la existencia (esto es, del ente nichtdaseinsmäßig). Pues Heidegger no parece tener en cuenta esta posibilidad en su texto del 27 cuando rápidamente reconduce la cuestión a plantear cómo 
la Realität, que asocia al estar ahí delante (Vorhandenheit), ha de ser comprendida desde un modo previo de ser, propio del trato pragmático y circunspecto con el mundo, esto es: lo a-la-mano (Zuhanden). De nuevo aquí se expresa el temor de Heidegger a dejar la puerta abierta, con la aceptación de la idea de realidad, a postulados teoréticos que priorizan el modo de ser del Vorhanden, y que reflejan una idea del ser de lo ente como existente, conducente a pensar las cosas como objetos independientes, fuera de nosotros, que se quedan perennes esperando a que los descubramos.

El zubiriano vería entonces, un tanto decepcionado, cómo su noción de realidad quedaría ligada a un modo de comprensión cadente e impropio, elaborado a partir de la mera relucencia del «mundo» en el sentido de «totalidad del ente que puede estar-ahí dentro del mundo» (SZ, 64). Las tentativas por adoptar la realidad como categoría fundamental para pensar las cosas mismas quedarían mitigadas en SZ al constatar allí que cuando se parte del ente como real y «el ser cobra el sentido de realidad», entonces «la sustancialidad se convierte en la determinación fundamental del ser» (SZ, 201). La consideración del ente como real tendría que ver, entonces, con un modo cadente de comprensión que arrastra presupuestos metafísicos al hacerse una idea de las cosas como sustancias ${ }^{10}$.

Finalmente, el alumno zubiriano, al cabo de los años veinte, asimilaría que su única salida frente a Heidegger podría estar acaso en el afianzamiento de una postura propia desde la cual plantear sus objeciones. Su contraataque debería, además, respetar las exigencias del paradigma fenomenológico-hermenéutico hasta la medida de lo posible para no caer en un planteamiento netamente heteróclito. Por ejemplo, tratando de pensar qué concepto de experiencia podría pensarse como experiencia de lo real y, al mismo tiempo, no cayera en (i) una cosificación del mundo en la que se antepongan actitudes teoréticas al carácter efectivo de la cosa misma y (ii) que no arrastre presupuestos metafísicos como el de la sustancia. ¿Habría algún modo de conseguir un concepto tal

10 Podría sostenerse en este punto que las observaciones de Heidegger no podrían alcanzar a Zubiri en la medida en que el concepto de Realität como sustancia no es el sostenido por él. No obstante, el que las nociones de realidad en SZ, §43 y en Zubiri no coincidan no implica el que los argumentos de Heidegger no hicieran blanco en alguna medida. El propio Zubiri se tomó en serio estas críticas, como se desprende, por un lado, de las anotaciones que pueden observarse en su ejemplar personal de Sein und Zeit (disponible en la biblioteca personal del filósofo en la Fundación Xavier Zubiri), en el que la página 201 de esta obra se encuentra intensamente trabajada (con llamadas de atención a los textos que, intencionadamente, hemos citado) y porque, de hecho, en algunos pasajes dedicados a elaborar el concepto de realidad Zubiri trata denodadamente de descartar la noción de existencia y de sustancia. Sin ir más lejos, en el curso «Filosofía Primera» (1952-53) parece haber tomado nota de las observaciones de Heidegger cuando se pregunta si su idea de cosa real no haría decir a alguien de Freiburg que eso es, efectivamente, reducir el ser al Vorhanden (cf. AXZ, 0060005, p. 37), del mismo modo que en pasajes de Sobre la realidad dedicados a la discusión con Heidegger se toma claramente en consideración la tesis fenomenológico-hermenéutica de que la realidad es un modo de ser (cf. p.e. SR, 222). 
de experiencia? ¿Encontraría nuestro zubiriano alguna vía para entender las cosas mismas como realidades sin sustancializarlas? Quizás la solución pasaría por precisar un nuevo sentido de cosa, de res, o de ov̉oía. ¿Cuál sería ese concepto? Antes de verlo, consideremos el sentido desde el punto de vista fenomenoológico.

\subsection{La realidad del sentido: Heidegger de los años veinte desde Zubiri}

Por lo que a Heidegger concierne, en sus descripciones encontramos experiencias como la consabida de entrar en una clase y ver la cátedra del profesor (cf. GA 56/57, 70-71), conversar con los demás sobre el último semestre (cf. GA $58,43 \mathrm{ss}$ ), el paseo que doy por el bosque (cf. GA 58, 96), la reacción que me provoca escuchar una conversación sobre un partido de fútbol (cf. GA 58, 103), la experiencia del tiempo de los primeros cristianos (cf. GA 60, I), el modo en que trato la mesa como objeto para escribir (cf. GA 63, 90), e incluso la misma percepción es interpretada a la luz de esta idea de experiencia como trato circunmundano y significativo con el ente, como cuando habla no del sonido que produce el objeto «motocicleta», sino de la ruidosa motocicleta, de la carreta chirriante, etc. (cf. SZ, 163) o de escuchar el viento sur (SZ, 107), ejemplos que se prolongarán incluso hasta los textos de la Kehre, como por ejemplo en «El origen de la obra de arte» (cf. GA 5, 15-16). Ello basta para constatar cómo Heidegger opta por describir experiencias cotidianas (Trivialitäten, Alltäglichkeiten) de trato pragmático con el mundo, en lugar de atender a ingredientes de la experiencia que tienen que ver con las cualidades sensibles. Ahora bien, ¿cómo es juzgada desde Zubiri esta caracterización de la experiencia?

En los pasajes de la obra de Zubiri dedicados a la distinción entre cosarealidad y cosa-sentido se articula una idea de sentido que goza de una doble función: al tiempo que supone una crítica a Heidegger permite asignar un lugar a la aportación fenomenológico-hermenéutica desde dentro de la propia fenomenoología. Este lugar surge en un análisis de la cosa-sentido que permite describirla a partir del íntegro estar-en-el-mundo, en todas sus vertientes. En Zubiri esto significa reconstruir el concepto de sentido a partir de descripciones de la experiencia desde ingredientes no sólo intelectivos, sino volitivos y sentimentales, esto es, desde el punto de vista del fenómeno considerado física o noérgicamente. En coherencia con ello, el sentido sería un modo de presencia o, expresado en terminología zubiriana, de actualización de la cosa en tres líneas: (1) respecto al logos sentiente, (2) respecto a la vida humana y (3) respecto a la realidad como poder ${ }^{11}$.

(1) La cosa-sentido en el logos y en el campo de realidad.- En un principio sería admisible pensar que desde cierto punto de vista nuestra experiencia está larvada de significatividad: fenoménicamente constatamos que la aprehensión

11 Puede verse un tratamiento de esto ingentemente más amplio en Pintor-Ramos, A., Realidad y sentido. Desde una inspiración zubiriana. Salamanca: Serv. Pubs. Univ. Pontificia Salamanca, 1993, pp. 143-188. 
de las cosas mismas tiene lugar en un trato pragmático, de acuerdo al cual los objetos comparecen en función del uso que le damos y de cómo nos los apropiamos como posibilidades. Ahora, Zubiri plantea que es posible dar un paso más por debajo del sentido hacia un mundo de pre-significatividades. El análisis fenomenoológico distingue un nivel previo a la propia apertura comprensora e interpretante del mundo cuando mantiene que no vemos cosas tales como mesas, sino más bien sistemas de notas que en mi vida tienen función o sentido de mesa (cf. IRE, 59). Dentro de la experiencia significativa del mundo hay un componente que aparece no en función de la vida humana o del Dasein, sino que, en la medida en que debe pertenecer intrínsecamente a la cosa misma (esté o no apropiada por el Dasein), constituye la posibilidad de que aparezca el sentido y, por ello, es pre-significativa. Aunque yo puedo describir la experiencia como significativa si atiendo al modo fenoménico como los objetos comparecen inmediatamente en medio de mi vida, el punto de vista fenomenoológico añade que estructuralmente hay otros componentes a la base de estas significatividades, que principalmente tienen que ver con caracteres sensible-intelectivos de la experiencia. Esto le conduce a plantear frente a la idea de compresión de sentido que la aprehensión del fenómeno nos da la captación de su contenido formalizado como alteridad, esto es, como algo otro "de suyo». A esa aprehensión, también denominada primordial, la acaba llamando impresión de realidad.

En esta línea, la distinción entre comprensión e impresión conlleva el rechazo a que el sentido constituya lo originario del aparecer de la cosa, desplazándolo a un lugar derivado. ¿Qué lugar es ese? Zubiri lo deja claro, al menos en un primer momento, cuando escribe que «Yo no aprehendo mesas, pero tengo un logos de las mesas, y en general de toda cosa-sentido» (IRE, 277) y que «sólo las cosas reales, entendidas en el sentido antes expuesto, pueden tener y tienen esencia. De las "cosas-sentido" hay concepto, pero no esencia» (SE, 107). Esto es, el sentido es el modo de actualidad de la cosa en respectividad con un nivel ulterior a la aprehensión primordial, que Zubiri llama logos sentiente y cuyo contenido lo constituye un campo de realidad en el que la cosa experienciada se determina en función de otras cosas ya previamente aprehendidas. Esto es, para que el sentido aparezca sería necesario que la intelección ya hubiera aprehendido previamente otras cosas en función de cuyas notas reales, tales como peso, forma, color, tamaño, etc. se elabora su significatividad. La cátedra del profesor, según el ejemplo de Heidegger en el KNS 1919, comparece como tal gracias a que aprehendemos una cosa con unas determinadas características físicas como peso, color, tamaño que nos indican algo que, en el contexto del mundo universitario, podrá ser una cátedra pero nunca, sin ir más lejos, un objeto-para-volar.

(2) La cosa-sentido en la vida humana.- De ahí que fenomenoológicamente el sentido sea caracterizado frecuentemente como «el carácter constructo de las cosas como momentos de la vida humana» (SE, 291). La cosa realidad se constituye como cosa-sentido sólo cuando aquella es actualizada con respecto a la vida humana en el campo de realidad, no con respecto a cualquier otra cosa. Ese respecto vendría a expresarse, a nuestro juicio, en el por-mor (Worumwillen) por el que comparece el ente en la apertura comprensora del Dasein (vid. 
SZ, 84). Según escribe Zubiri, «Para que haya cosa-sentido (...) es necesaria una respectividad a una sustantividad que actúe para la sustantividad y en vista de la sustantividad. Es decir, hace falta una respectividad al hombre» (SSV, 233; vid también SR, 224 y EDR, 228).

Esta respectividad al ser humano tiene que ver también con ingredientes volitivos, ya que la apropiación de posibilidades implica, según el planteamiento zubiriano, que la cosa esté actualizada no sólo intelectivamente, sino también en una opción libre. Esto le lleva a plantear que la realidad tiene un cierto carácter transcendental de bonum: las cosas tienen la capacidad para constituirse en bienes, en recursos, en ser fuente de posibilidades que pueden ser apropiadas por el ser humano para definirse a sí mismo (cf. SE, 429-430; SSV, 38).

Ahora, que el sentido se defina desde la apropiación le sirve a Zubiri para situar con precisión uno de los elementos fundamentales de la analítica existencial y, en general, de la ontología fenomenológica de Heidegger: el tiempo. El Dasein se apropia del ente como posibilidad o recurso debido al carácter radicalmente tempóreo de su existencia, que es abierto propiamente cuando ésta es tomada de cara a su muerte, esto es, al futuro. Zubiri considera que con ello, en la medida en que la temporeidad acaba erigiéndose como el sentido del ser del Dasein y, aún más, en la medida en que al final de SZ se plantea el tiempo mismo como el horizonte del sentido del ser del ente en general, con todo ello se haría del tiempo la realidad misma (vid. p.e. SH, 624, 628; AM, 71-74). Realidad que, en el fondo, por quedar temporalizada tendría a ojos de Zubiri la condición de irrealidad (vid. SE, 108).

(3) La cosa-sentido respecto al poder de lo real.- Ahora bien, aunque el sentido sólo surja en respectividad con la vida humana, la tesis fenomenoológica fuerte mantiene que no son las notas de la vida misma las que constituyen la condición del aparecer del sentido, sino sus notas reales. l.e., es condición necesaria que la cosa se dé en un campo de realidad en el que la cosa sea apropiada por la vida humana, pero esto per se no costituye condición suficiente para el surgimiento del sentido. De ahí que Zubiri escriba que

«lo decisivo no está en el sentido de la vida real, sino en que la vida sea una realidad que, por ser ella misma lo que es como realidad, tienen que tener sentido. El problema no es el sentido de la realidad sino la realidad del sentido mismo como momento real de la vida real» (SH, 206).

La condición del sentido no aparece solamente al considerar las cosas en el contexto de la vida, sino cuando este contexto mismo es considerado desde su realidad física. Y ello por la razón de que la relación entre cosa real y cosasentido es tal que a la cosa le tiene sin cuidado (¡sin Sorge!) quedar constituida en tal o cual sentido:

"Que una oquedad en una montaña sea una caverna y habitación de un hombre, le tiene sin cuidado al fenómeno geológico. Pero si el hombre pretendiese, por lo menos en cosas artificiales, hacer una puerta que fuese de humo... Esto no podría hacerse. Quiere decir que no todas las cosas poseen la misma capacidad para tener un sentido determinado» (EDR, 228). 
No se puede hacer una puerta de humo porque las notas físicas del humo no tienen la capacidad necesaria (solidez, por ejemplo). La condición necesaria del sentido sería, según Zubiri, el carácter físico o real de las notas aprehendidas impresivamente, no comprensoramente.

Y bien, precisamente la condición intrínseca de las cosas para constituirse como posibilidades para la vida humana radica en que la realidad tiene un carácter de poder (cf. EDR, 235). Lo real, por ser el momento formal de las notas, es «más» que las notas mismas. El color que se actualiza en mi impresión lo hace como perteneciendo "de suyo» a lo aprehendido mismo, momento que siempre es algo "más» que el mero color aprehendido. La realidad tiene en este sentido un "efecto de dominio" sobre el contenido que adquiere la vida humana al apropiarse de posibilidades (cf. HV, 144). De hecho, es precisamente este carácter de poder de lo real el que permite a la vida humana apoyarse en algo para realizarse a sí misma, y sin lo cual no tiene nada que le asista. No es de extrañar que la cuestión de la realidad como condición del proyecto de posibilidades de la vida humana conduzca ulteriormente a la temática de la religación ${ }^{12}$, en cuya elaboración se parte de la realidad como apoyo último, posibilitante e impelente.

\subsection{Matización de la crítica de Zubiri al sentido}

La consideración del sentido como algo campal o propio del logos, que es construido volitivamente por apropiación humana y gracias al poder de lo real ha llevado a Zubiri a emitir una valoración en ocasiones bastante cruda del mismo. Como se ha entendido el sentido como posibilidad abierta en la apropiación volitiva de la realidad, Zubiri en ocasiones ha acabado haciendo del sentido algo que flota sobre sí mismo o arbitrario. J. E. Rivera comenta en alguno de sus textos que Zubiri, al referirse a Heidegger, siempre solía señalar que no se puede envolver un regalo con agua ${ }^{13}$. Esto significa: tan sólo con la comprensión de sentido nos quedamos en una apropiación arbitraria de los entes que no puede explicar por qué unas apropiaciones son posibles y otras no. Esto se debe a que Zubiri tiende a identificar la categoría de sentido o posibilidad en el contexto de la fenomenología hermenéutica heideggeriana con el puro proyectar (Entwurf), como una «arbitraria posibilidad de que el hombre echa mano ad libitum» (SE, 447).

Hasta ahora hemos dejado en la oscuridad la figura de algún hipotético heideggeriano que pudiera replicar a Zubiri, pero precisamente en este punto podemos invitarlo a salir a la palestra: ¿Podría admitir esta conclusión un

12 Vid. «El problema teologal del hombre: el hombre y Dios» [Curso de Roma] (1973), HD, pp. 398-399.

13 Cf. p.e. Rivera, J. E., «Zubiri y Heidegger», en Nicolás, J. A. / Espinoza, R., Zubiri ante Heidegger. Barcelona: Herder, 2008, p. 26. 
heideggeriano ${ }^{14}$ o el Heidegger mismo de los años veinte? Inmediatamente, el heideggeriano podría replicar que la concepción zubiriana del sentido como un mero Entwurf construido arbitrariamente no refleja el hecho de que en Sein und Zeit éste se entiende en unidad con el estar arrojado (Geworfenheit) y, coextensivamente, con la facticidad. Las exposiciones de Zubiri sobre SZ parecen prescindir con frecuencia — quizás conscientemente- de que según lo expuesto en el $§ 31$ el esbozo de posibilidades se funda en una facticidad que impide que aquel «flote sobre el vacío»:

«La posibilidad en cuanto existencial no equivale a un poder-ser que flota en el vacío [freischwebend], a la manera de la indiferencia de la voluntad (libertas indifferentiae). El Dasein, en cuanto afectivamente dispuesto, por esencia, ya ha venido a dar siempre en determinadas posibilidades. (...) esto significa: el Dasein es un ser-posible entregado a sí mismo, es, de un extremo al otro, posibilidad arrojada [geworfenes Entwurf]» (SZ, 144).

Las posibilidades no son sacadas de la existencia por sí misma, sino de la facticidad en la que ésta se encuentra no sólo arrojada, sino ligada. Así es como precisamente traduce J. E. Rivera el texto de SZ en el que se define la facticidad: «el estar-en-el-mundo de un ente "intramundano", en forma tal que este ente se pueda comprender como ligado [verhaftet] en su destino al ser del ente que comparece para él dentro de su propio mundo» (SZ, 56). En SZ la facticidad constituye la condición indispensable e irrebasable a la cual se está ya siempre plegando el Entwurf. En esta línea hay algunos pasajes en los que la interpretación de Heidegger explicita que el Dasein nunca es tan absoluta e incondicionalmente libre como para darse a sí mismo la medida de su proyectar, sino que siempre ha de anclarse en la cotidianidad fáctica, que jamás puede borrar (cf. SZ 179, 371).

No obstante, una vez matizado esto, sí creemos que la crítica de Zubiri acierta de pleno en una cuestión que podría ser incluso asumible desde el ámbito heideggeriano. Lo que, a nuestro juicio, se pone de relieve en la crítica zubiriana no es la incapacidad de la fenomenología hermenéutica para explicar por qué no podemos envolver con agua un regalo, sino la incapacidad que tiene la ontología heideggeriana para explicar cómo se constituyen las posibilidades a partir de lo ente en general, no sólo en función del Dasein. Al final de la sección de Sobre la esencia dedicada a Heidegger, Zubiri niega la prioridad del ser (y, por ende, del sentido) «porque el ser carece de

14 R. Rodríguez, por ejemplo, no la admite. Mantiene que la fenomenología hermenéutica es perfectamente capaz de dar cuenta de en qué casos se puede interpretar el ente como tal a diferencia de otros casos en los que la red de significados no lo permite y transfiere la responsabilidad explicativa al planteamiento zubiriano por cuanto le pide que explique qué añade la realidad al sentido que éste no tenga ya, finalizando en una consideración que asimila la cosa-real zubiriana con el Vorhanden (cf. RodríGuez, R., "Comprensión de sentido e impresión de realidad», en PINTOR-Ramos, A., Zubiri desde el s. XXI. Salamanca: Serv. Pubs. Univ. Pontificia Salamanca, 2009, pp. 261-280). Emplazamos para otro lugar nuestra propia respuesta a este valioso planteamiento crítico. 
toda sustantividad; el ser sólo es "respectivamente"; y esta respectividad no es la respectividad al hombre, sino a la realidad de todo» (SE, 453). El problema del sentido, tal como queda situado en SZ, acaso consista en que sólo permite acceder al darse efectivo de la cosa pero estrictamente para el Dasein (por-mor de él o Worum-Willen, vid. SZ, §18, 84). Aquí podría estar, quizás, el aspecto más fuerte que la crítica de Zubiri pone de relieve al enfrentarse a Heidegger: el sentido del ser, como posibilidad, sólo es respectivamente al Dasein, al viviente humano. El sentido es el modo como la cosa misma es abierta, pero en la medida en que ese descubrirse caiga bajo la categorización de la significatividad (Bedeutsamkeit), no puede ser capaz de dar cuenta del ser de lo ente en general, sino sólo de lo ente en cuanto cae bajo el trato circunspecto del Dasein.

Precisamente, el ámbito que podría conducir a la fenomenología hermenéutica más allá de la analítica existencial podría estar más ligado a la facticidad y no a la existencialidad, que, según creemos, asume un papel excesivamente prioritario en el análisis del ser del Dasein en SZ. Posiblemente Zubiri pone el dedo en la llaga cuando incide en que el futuro es designado como momento tempóreo privilegiado de la apertura del Dasein en el modo propio. Al desplazar el peso del momento del futuro sobre otros como el presente o el pasado, la estructura del estar-en-el-mundo analizada en SZ se desplaza hacia los momentos comprensores, proyectivos y que tienen que ver con la existencialidad. Esto lleva aparejada una priorización de estructuras tales como el Selbstwelt (el quién de la existencia: la Sorge), el comprender y la interpretación (Verstehen-Auslegung), así como el Entwurf. Acaso este desplazamiento pueda estar a la base de la caracterización de la experiencia como eminentemente significativa, quedando en cambio otras zonas de la estructura del estar-en-el-mundo desaprovechadas, tales como la facticidad, cuyo desarrollo prioritario quizás podría haber proporcionado resultados diferentes a la hora de caracterizar la experiencia. Ingredientes fácticos de la existencia como la Geworfenheit, la experiencia fáctica del Umwelt así como la condición respectiva de lo ente o Bewandtnis quedan por ende entendidos desde los existenciales ${ }^{15}$. De ahí que interpretaciones de SZ como las de Zubiri quizás tienen que ver con la pretensión de señalar un desplazamiento desde la facticidad de la experiencia a la existencialidad de la misma, en el que la primera queda asumida en la segunda.

15 Esto se traduce en algo que de hecho venía sucediendo ya desde las lecciones tempranas de Friburgo y que algunos como R. RodRíguez (aunque, desde luego, sin llegar a la derivación crítica con Heidegger que nosotros sostenemos de la mano de Zubiri) han reconocido: que en la fenomenología hermenéutica el Vollzugssinn y, con ello, el Selbstwelt, adquieren un predominio sobre las demás direcciones intencionales de la vida fáctica. Véase p.e. GA 58, 59-62, 95-96, 101-102, donde se destaca la experiencia del mundo propio (Selbstwelt) como aquel en que la fenomenología hermenéutica debe centrarse y conquistar. 
3. LA OUSíA DEL SENTIDo y DE LA REALIDAD: EL HABER EN HEIDEgGER y ZuBIRI.

Una vez reconocido el similar punto de partida que, sin embargo, conduce a claras desavenencias, ¿dónde encontrar un centro común? En la interpretación que hemos sostenido Heidegger y Zubiri parecen más alejados que nunca. Pues bien, pensamos que justo en los puntos a que conducen, en cada caso, las críticas a la realidad y al sentido, y en las exigencias que de estas críticas se desprenden está la posibilidad de encontrar una productiva afinidad común.

Al ver la realidad desde los parámetros establecidos desde la fenomenología hermenéutica apareció el requisito de no considerar la experiencia como percepción sensible si ello tenía lugar bajo una consideración teorética que hiciera de la sustancialidad la determinación fundamental del ser del ente. ¿Habría entonces alguna manera de pensar la cosa misma como cosa real sin caer en semejantes postulados? Por otro lado, al contemplar el sentido zubirianamente desde la realidad se atisbó cómo la existencialidad es insuficiente para dar cuenta del todo del ente en general, dejando en la sombra el carácter de la facticidad. ¿Habría alguna manera de recuperarlo desde Heidegger frente al privilegio de las estructuras que tienen que ver con la existencialidad, de modo que fuera posible encontrar dimensiones más allá del sentido y de la Bedeutsamkeit?

Nuestra propuesta, en la que radica ese centro común, es que la respuesta a ambas cuestiones es la misma tanto para Heidegger como para Zubiri. Y ésta pasa por la determinación de la experiencia desde el concepto de haber en el sentido prefilosófico del término griego ov̉oía. Tanto uno como otro llevan a cabo una profundización en la filosofía griega en la que tratan de extraer rendimiento filosófico de algunos conceptos característicos. Al prestar atención a la categoría aristotélica de sustancia (ov̉oía) constatan que, a su vez, este término gozaba al mismo tiempo de una significación pre-filosófica, no técnica, que en tiempos de Aristóteles era usada para referirse a los bienes, recursos, pertenencias, posesiones o haberes que permiten tener suficiencia en la vida ${ }^{16}$. Heidegger va a hallar en este sentido de ov̉oía una manera de pensar el ser no contaminada aún, por así decirlo, por las conceptuaciones metafísicas platónicas y aristotélicas (vid. p.e. GA 62, 373-4; GA 18, 24-6; GA 24, 449). Y por su parte Zubiri encontrará aquí una posibilidad conceptual para pensar el contenido de la experiencia más allá del ser y, al mismo tiempo, sin caer en una teoría metafísica de la sustancialidad (vid. p.e. CU-I, 455; CU-II, 185; CU-III, 98; NHD, 121-6). La clave para ello está en que la ov̉oía como haber expresa la experiencia de las cosas como posesión, como pertenencia de la cosa a símisma. Veámoslo primero en Heidegger.

16 Cf. Liddell / Scott / Jones, A Greek-English Lexicon. Oxford, 1882, pp. 1274-5. 


\subsection{Haber y Ereignis (Heidegger de los años veinte)}

En el caso del alemán la dimensión del haber es justamente la que permite abarcar regiones de la experiencia que no tienen por qué pensarse exclusivamente desde el sentido y la significatividad. Precisamente a esta dimensión experiencial del haber es la que nos abre la facticidad en el Heidegger de los años veinte; concepto en el cual, según se infiere de algunos textos concretos, se debería contener una determinación más amplia que la de la mera existencialidad. Por ejemplo:

«Facticidad y existencia no significan, pues, la misma cosa, ni el carácter ontológico y fáctico de la vida está determinado por la existencia; la existencia es sólo una posibilidad que se despliega temporalmente en el ser de la vida que se ha definido como fáctico. Pero esto significa que la posibilidad de un planteamiento radical de la problemática ontológica de la vida descansa en la facticidad» (GA 62, 362; trad. J. A. EscudERo en Interpretaciones fenomenológicas sobre Aristóteles. Madrid: Trotta, 2002).

En este texto Heidegger entiende la idea de facticidad como algo que no se reduce a ser término de un esbozo de posibilidades y, por ende, como algo distinguible de la pura Existenzialität. La facticidad seria en este sentido un carácter más radical que el de la existencialidad. Ahora bien, ¿ha sido transitado efectivamente este carácter de la experiencia en busca de la determinación del ser de lo ente desde ello? ¿O más bien ha prevalecido en Heidegger el rasgo de la existencialidad, más vinculado al Dasein mismo? De conceder la primacía en la estructura de la existencia a la facticidad, ¿qué nos encontraríamos?

En concreto, en SZ la facticidad es el existenciario que está a la base de la Geworfenheit. Pero, además, cada uno de los existenciarios que constituyen el estar-en en cuanto tal (facticidad (estar arrojado), existencialidad (esbozo de posibilidades) y caída tienen que ver correlativamente con los momentos que estructuran la situación hermenéutica: haber previo (Vorhabe), manera previa de ver (Vorsicht) y conceptuación previa (Vorgriff) (vid. SZ, §32) ${ }^{17}$. De este modo, la facticidad se encuentra conectada con una condición de la interpretación que Heidegger llama precisamente haber previo. Las cosas están dadas en un momento preparado de antemano (según denota la expresión en el alemán cotidiano) y que en la fenomenología hermenéutica alude a un ámbito de predonación de la cosa misma que fija el alcance y guía la dirección de los pasos ulteriores de la pre-comprensión (cf. SZ, 232). Ese ente tenido de antemano en el Vorhabe funda el estado interpretativo del Dasein (Ausgelegtheit), está a la base del mismo, es la razón por la cual «cada ser humano lleva consigo un fondo de comprensibilidad e inmediata accesibilidad» (GA 58, 34). Heidegger utiliza aquí la expresión Fonds, que suele tener eminentemente una connotación financiera. El «fondo» es el capital que tiene alguien en su haber y que le permite

17 Vid. también v. Herrmann, F.-W., Weg und Methode. Frankfurt: V. Klostermann, 1990, pp. 18-20. 
tener cierto grado de autosuficiencia. Eso nos lleva a preguntarnos: ¿por qué este momento es precisamente un Vor-habe? ¿Qué aporta exactamente la idea de que este momento fundamental sea un Haben?

Por un lado, podría decirse que la experiencia, en la medida en que es un comportamiento con el ente (Verhalten zum Seiende), sería también una $\varepsilon^{\prime} \xi \xi \iota$, , un habérselas fáctico con las cosas cuya facticidad conlleva, contra lo que pudiera parecer, un grado suficiente de claridad que permite a la cosa hacerse disponible (verfügbar):

«La experiencia es un determinado comportamiento en el cual algo se me hace accesible en el mundo de la vida; de modo que lo que yo veo me lo «apropio» de algún modo, de tal manera que lo experienciado se hace disponible tal como me aparece...» (GA 58, 208).

La facticidad se encuentra imbuida de una inevitable dimensión de posesión de la cosa en el sentido de que es la cosa quien se deja poseer (besitzt) desde lo más propio de sí misma.

Ello tenía que ver, además, con la idea de experiencia que venía siendo tematizada ya desde el curso del KNS 1919 con el término Ereignis entendido como apropiación originaria. Heidegger introduce allí la distinción entre una caracterización de la experiencia como proceso (Vorgang) y como apropiación (Ereignis). En la primera - como ya vimos-, propia de la actitud teorética que desconecta lo que tiene la vida de ejecución y la ausculta desde intereses epistemologicistas, tiene lugar una desvivificación de la experiencia (Entlebung) en la que las cosas son vistas como desde fuera de ellas mismas. En cambio, en la segunda la vida llega a lo más propio de sí misma desde una perspectiva que arroja la experiencia desde dentro de la cosa (cf. GA 56/57, 75). En la experiencia de la cosa "por dentro» sucede que lo vivido no pasa por delante de mí, inerte, sino que «yo mismo me lo apropio y la cosa se apropia de sí misma según su esencia» (cf. ibid.). En este sentido, las vivencias o experiencias son apropiaciones originarias (Er-eignisse), en la medida en que, para reproducirlo con el lenguaje heideggeriano, ellas viven de lo que les es propio y sólo así viven (cf. ibid.): esto es, en la experiencia la cosa se da desde su propiedad, desde lo que le es más propio en su pertenecerse a sí misma, desde el propio ámbito que ella instaura. Podría decirse entonces que la experiencia consiste, además, en un cierto ह̌ $\chi \varepsilon i v$, en una tenencia en la que la cosa misma es accesible en propio, en su propiedad (Besitz, Eigentum $)^{18}$ en el doble sentido: como siendo mía y como siendo lo que ella es propiamente.

18 Von Herrmann rechaza precisamente esta identificación en Hermeneutik und Reflexion (Frankfurt: V. Klostermann, 2000, p. 51). Sin embargo, J. A. Escudero ha puesto de relieve la conexión de las expresiones como eigentlich o Eigen con la idea griega de idios y la latina de proprius, emparentados, a su vez, con el ě $\chi \varepsilon ı v$ y el habere, según el Diccionario alemán de los Hermanos Grimm, en el cual Heidegger se apoyaba para preparar sus lecciones (cf. Escudero, J. A., El lenguaje de Heidegger. Barcelona: Herder, 2009, pp. 70s). La raíz -eignen presente en Er-eignis connotaría así la idea de apropiación en el sentido de propiedad que tiene cada uno en su haber, en su posesión y que le permite ser autosuficiente en la vida. 
La experiencia desde el haber como habitud ( $\left.\xi_{\xi} \xi \varsigma\right)$ y como tener en propio ( $\check{z} \chi \varepsilon i v)$ serían expresiones susceptibles de expresar en clave fenomenológica la cosa misma desde el carácter de propiedad, no sólo desde el de ser o de significatividad. Y ello por la razón de que la idea de haber le sirve a Heidegger en determinados pasajes para atisbar algo más allá del ser. En Die Lehre vom Urteil im Psychologismus (1913) Heidegger comenzaba su andadura examinando los juicios impersonales y preguntándose por su sujeto. Por ejemplo, el juicio «truena» (es blitzt) encontraría en el contexto la respuesta a ello (vid. GA 1, 185186). Ya en los años veinte otra expresión impersonal, es gibt, aparecía ligada a la cuestión de la descripción de lo dado (das Gegebene) o del algo en general (Etwas allgemeines) (vid. p.e. GA 56/57, 41, 62). De hecho, en los años tardíos de Marburgo la expresión «es gibt» es recuperada a la hora de expresar de una manera coherente el carácter de ser del ente, como en algunos pasajes de Sein und Zeit: «Ser — no el ente- sólo lo hay en tanto que la verdad es» (SZ, 230; vid. también 316) y para introducir el tema de la diferencia ontológica en el SS 1927 (vid. GA 24, 13-14). Al tratar de expresar el ser no puede usarse de nuevo el mismo término, pues lo que caería bajo el concepto «ser» sería el ente. Para esquivar esta dificultad, Heidegger escribe "el ser se da o hay» (es gibt). Con ello tendríamos un término, es gibt, que sirve tanto para conceptuar el darse originario del algo en general, como para expresar qué es el ser sin recurso al ser mismo.

Más adelante, en el mismo curso, tantearía esta posibilidad en cambio por la vía de la determinación temporal del ente en general, para lo cual introduce la idea de presencia (Praesenz y Anwesenheit) como esquemas temporales del horizonte del ente que no tiene el modo de ser de la existencia (nichtdaseinsmäßig). Ahora bien, Anwesenheit significa también lo presente como haber, como ov̉oía, como hacienda o capital del que dispongo. El recurso a la Anwesenheit como hacienda podría funcionar, de ser conectado con la significación prefilosófica de la ov̉oía como haberes, para expresar la presencia de la cosa no como significativa por-mor del Dasein, sino como algo más allá de la significatividad, siendo algo en propio de la cosa misma. Los términos de $\check{\varepsilon} \xi ı$ y $\check{\varepsilon} \chi \varepsilon ı v$ darían cuenta precisamente de la experiencia como un haber de la cosa en su propiedad, en el que ésta se da en una apropiación originaria (Ereignis).

\subsection{Haber $y$ «de suyo»}

Por su parte, en Zubiri vamos a encontrar algo muy similar, que surge al considerar cómo la noción de cosa real supone una profundización en el sentido prefilosófico de ov̉oía. Profundización que, por otro lado, va desarrollándose

Lo que le basta a uno para vivir sin más, o, podríamos decir en consonancia con conceptos heideggerianos, el carácter de autosuficiencia (Selbstgenugsamkeit) que tiene la vida para el que se apropia de ella (vid. p.e. GA 58, 42). 
a lo largo de varias etapas en las que la denominación del sentido de esta como haber se va transformando hasta cierto punto. Veámoslas en tres pasos ${ }^{19}$ :

En primer lugar, hay un período en la producción zubiriana, básicamente la etapa ontológico/metafísica, en el que la expresión «haber» se emplea para referirse a una instancia más allá del ser, como resulta evidente en algunos pasajes de «En torno al problema de Dios» (NHD, 436) y que, además, estaría estrechamente vinculada a la experiencia sensible, como se desprende de «Ciencia y realidad» (1941): «en la sensibilidad visual, por ejemplo, no se produce sino un mero "haber color"» (NHD, 115). Esto nos permite hablar en Zubiri de una idea de haberes expresada desde un habérselas o $̋ \xi \xi \varsigma$ que es sensible, y desde la interpretación de ov̉øía como recursos o posibilidades de vida. La idea de habérselas sensible va a conducir a la impresión de realidad al hilo de un logro conceptual que Zubiri alcanza ya desde esta etapa y que tiene que ver con la distinción entre el carácter de la ov̉oía o haber como recurso por un lado y como fuente de esos mismos recursos por otro:

«Lo que llamamos sustancias son cosas que están ahí: a la disposición de uno, son nuestro capital, o haber = ousía. Pero nótese: este capital es mi capital porque lo que está ahí tolera serlo, es decir, porque es cosa. Está a mi disposición porque la cosa posee por sí misma todo cuanto tiene. Es una fuente permanente de que yo puedo echar mano. Fuente permanente de su manifestación = ousía» (CU-III, 98).

Esa fuente de posibilidades sería más tarde la realidad, cuya noción aparece ya en la definición de la misma en algunos textos de esta etapa, como en "Res cogitans» (1937): "cualquier cosa que se basta a sí misma para actuar; cualquier cosa que encuentra en sí misma los recursos, por así decirlo, de su vida» (SPF, 293).

Hacia el final de la década de los años cuarenta, Zubiri aún ve estrechamente vinculados el haber y la realidad. En concreto, al hilo del curso "Sobre las Ideas de Platón» (1947-48) Zubiri comienza un proyecto de libro «Sobre el sentido del ser en Grecia» (1947), cuyos apuntes están disponibles en el AXZ. En "Ciencia y realidad» al hablar de la ov̉oía había indicado en una lacónica nota a pie de página que «la etimología de la palabra ousía está aún sin precisarse» (NHD, 124n1). Acaso con ello pudiera estar refiriéndose a la disquisición que lleva a cabo en los apuntes referidos de cara a la elaboración de aquel libro sobre los griegos. En este escrito se puede seguir la búsqueda de Zubiri de verbos de realidad (griegos y latinos en su mayoría) a través de los cuales pueda expresarse esa doble dimensión que encierra el concepto de ov̉oía como recursos y como fuente de los mismos. Doble dimensionalidad que, por otra parte, sigue manteniendo cuando, al poner el ejemplo de en qué consiste la realidad de un útil como un cuchillo, distingue entre su àyafóv en el sentido de utilidad

19 Hemos examinado con mayor detenimiento el devenir de estas etapas en Gómez DeLGADO, J. M., «Evolución de los conceptos de sentido y realidad en la recepción zubiriana de Heidegger», Cuadernos Salmantinos de Filosofía, 41 (2014), pp. 149-172. 
con vistas a un para-qué y su usabilidad en cuanto posee la capacidad de ser un buen o mal cuchillo para cortar por lo bien o mal hecho que está ${ }^{20}$. De aquí deriva uno de los descubrimientos cruciales, a juicio de Zubiri, de los griegos: la idea de la cosa como algo que tiene de suyo las capacidades para ser lo que ella es. Es el «suyo» de la cosa anterior a todo "para» ${ }^{21}$.

A fin de dar cuenta de este "suyo», Zubiri va pasando revista a diversos verbos, entre los cuales atiende especialmente a los de posesión, tales como кá $\varepsilon \varepsilon \omega$

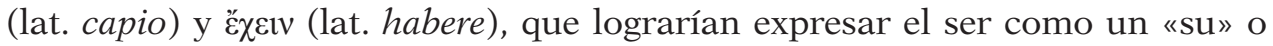

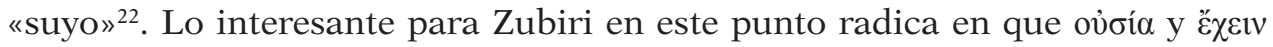
parecen converger por cuanto expresan la cosa como un "por sí», sentido en el que, teniendo en cuenta que ov̉oía es la sustantivación (participio) del verbo عĩval, supondría que el ser puede tener el sentido de posesión, como en el uso de

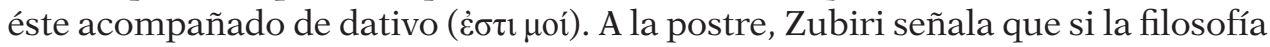
hubiese tomado el ser en su sentido posesivo en lugar de atender sólo al existencial y al predicativo aquella habría tenido otro carácter ${ }^{23}$. Probablemente: en el sentido de haber descubierto la suficiencia de la cosa no en la línea de la sujetualidad (del hypokeímenon como sujeto de inherencia de los accidentes), sino en alguna otra distinta, como acabaría siendo, dicho con la vista puesta años más tarde, la sustantividad.

Sin embargo, en esta trayectoria filosófica convive otro término junto con el de haber: el verbo estar. En la definición de «real» en «Res cogitans» se afirmaba que «lo real es cualquier cosa que se basta a sí misma para actuar». El «bastarse a sí misma» alude al haber, a la ov̉oía; mientras que el "para actuar» refiere a algo en cierto modo distinto, pero que también halla fuentes documentales en el Zubiri de esta misma etapa ontológica o metafísica. En «El ser sobrenatural: Dios y la deificación en la teología paulina» (1944) ya se distingue, a raíz del concepto de ser y del problema del movimiento en Platón y Aristóteles, entre

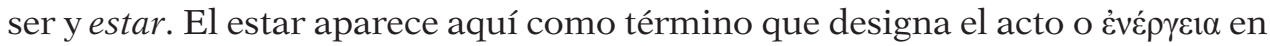
el que la cosa está siendo, esto es, su actualidad en el sentido de algo que está ahí, que se encuentra efectivamente (NHD, 466-7).

El estar como efectividad o actualidad de la cosa es un motivo conceptual que, si bien durante un tiempo convive con el de haber, a medida que Zubiri vaya precisando los contornos conceptuales de su pensamiento va a ir desplazándolo claramente. Aunque situar la fecha exacta del abandono del término «haber» para expresar la realidad es quizás difícil y arriesgado, está claro que al menos hacia comienzos de los años 50 éste acaba siendo sustituido por el de estar. Es así que en los textos del curso «Filosofía Primera» (1952-53) tanto el ser como el haber aparecen ubicados en el mismo nivel: esto es, el referido al momento de presentidad de la experiencia, fundado sobre una previa presentación, expresable mediante la fórmula — que podría tomarse como contestación a la

20 «¿Qué son las ideas?»(1947-48), AXZ, 0052002, p. 36.

21 Esto aparece añadido en una papeleta a la misma página anteriormente citada.

22 «Sobre las Ideas de Platón. Introducción y dos capítulos», AXZ, 0033002, pp. 38-39.

23 Op. cit., p. 47. 
heideggeriana In-der-Welt-Sein- «estar en la realidad» ${ }^{24}$. Asimismo, el desplazamiento del haber al estar es incluso constatable a través de los referentes que en un pasaje de Sobre la esencia usa como ejemplos de cosa sentido: una mesa, una hacienda agraria (SE, 105). Es llamativo el ejemplo, pues, si recordamos, hacienda agraria puede traducirse al alemán como Anwesen, que tiene también el significado de bienes, de posesiones, en clara cercanía semántica con ov̉oía.

¿Significa esto que el «haber» desaparece del pensamiento zubiriano? Sí lo hace claramente en el sentido de ser sustituido por el verbo «estar» como término idóneo para expresar la realidad efectiva y física de la cosa. La expresión máxima de ello la tenemos en un texto de Inteligencia y logos, uno de los pocos en los que, retrospectivamente, Zubiri menciona en pasado que durante un tiempo usó el verbo «haber» para referirse al carácter real de las cosas (cf. IL, 349-350).

Ahora bien, lo que permanece aún a través de la sustitución del haber por el estar es lo que designaba el haber mismo en su doble dimensionalidad: no sólo la cosa como recurso, como haber apropiable por y para la vida, sino como fuente de posibilidades por su carácter de suficiencia. Pero, ¿acaso no es esto lo que se mantiene en la noción de cosa real tal como se encuentra en los escritos de madurez? La definición de cosa real como "aquella que actúa sobre las demás cosas o sobre sí misma en virtud de las notas que posee "de suyo" " (IRE, 60), que antaño caracterizara como cualquier cosa que se basta a sí misma para actuar, que encuentra en sí los recursos (cf. SPF, 293), ¿no menciona acaso la suficiencia propia de la ov̉oía prefilosófica? Asimismo, expresiones del tipo "de suyo», «en propio», ¿no tienen que ver con el carácter de autopose-

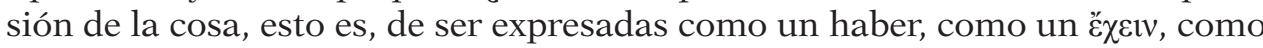
un «suyo»? Incluso el uso mismo de la noción «propiedad» en SE a la hora de hablar de las "propiedades» reales, que luego llamará «notas», como «todo aquello que pertenece a la cosa o forma parte de ella "en propiedad", como algo "suyo"» (SE, 104), ¿no tiene que ver con esa dimensión de la pertenencia de la cosa a sí misma que denotaba el haber ( $\left.\chi_{\chi} \chi \varepsilon i v\right)$ ? Si nuestra lectura es correcta, podemos hablar de un sentido mínimo en que permanece el haber en la noción contenida en el "de suyo», en el "en propio», siendo asumida positivamente en lo denotado por el «estar»: que el modo de pertencerse de la cosa (su haber, su «suyo» propio, su «de suyo») es físico, es efectivo.

\section{Conclusión: EREIGNIS (HeIDEGgER DE LOS AÑos VEINTE) $Y$ «DE SUYO» DESDE EL HABER}

¿No es éste sentido de haber como pertenencia de la cosa a lo más propio de sí misma lo que Heidegger encuentra en la experiencia de la facticidad bajo el nombre de apropiación originaria (Er-eignis)? ¿No podríamos ver en el intento de pensar la pertenencia de la cosa a sí misma en la experiencia uno de los hilos

\footnotetext{
24 Cf. «Filosofía Primera», AXZ, 0060, lección $18^{\text {a }}$.
} 
conductores fundamentales tanto de la fenomenología hermenéutica heideggeriana como de la fenomenoología zubiriana? Siendo así, ¿no supondría acaso el «haber» ese anhelado centro común a ambos? La realidad como «de suyo» y el Ereignis vienen a ser conceptos con los que tanto Zubiri como Heidegger apuntan al carácter radical de la cosa por el cual esta es algo en propio. Las cosas en la experiencia se presentan dejando un poso de propiedad que se nos patentiza en el carácter intencional de la misma: cuando aprehendemos objetos no podemos prescindir del carácter de suidad que presentan los contenidos de la experiencia, sean cuales sean. La experiencia humana capta objetos a través de la aprehensión del carácter de autopertenencia de estos, algo que podría expresarse tanto a través del «de suyo» como del Ereignis del Heidegger de los años veinte.

Ahora bien, resulta claro que la fenomenología hermenéutica apuesta claramente por hacer del ser y del sentido o significatividad los elementos a través de los cuales pensar esta propiedad. ¿Le aleja ello definitivamente de Zubiri? A partir de lo examinado en este trabajo proponemos un acercamiento entre ambos que se apoye en los elementos hallados en común y que tendrían que ver con el «haber» de la siguiente manera:

(i) El «haber» en el sentido de $\check{\xi} \xi 1 \varsigma$ podría conectarse bivalentemente con la caracterización del habérselas como comprensión de sentido e impresión de realidad. Lo que ambos tienen en común es que, en tanto uno como otro modo de habérselas con el mundo dan cuenta de la experiencia como una apropiación de la cosa desde lo más propio de sí misma.

(ii) Carácter de propiedad que, a su vez, se expresaría mediante otro sentido del «haber» que ha aparecido: como ह̌ $\chi \varepsilon v v$. Este indicaría la propiedad disponible en la experiencia que, independientemente de que la denominemos realidad o sentido, consiste radicalmente en un carácter de «su» o de algo que acontece desde una perspectiva originariamente interna a la cosa (Er-eignis, «de suyo» o «en propio»).

(iii) Finalmente, el sentido del haber como ov̉oía sería susceptible de, una vez destacado su origen prefilosófico, ser dotado de un alcance fenomenológico que permitiera atisbar una doble dimensión de la cosa: como recurso y como apta para servir como tal recurso por las propiedades que posee en propiedad.

El tránsito efectivo de Heidegger a Zubiri podría llevarse a cabo si, recurriendo al haber como centro común expresado en estos tres sentidos, explicitáramos concretamente cómo el Ereignis puede ser expresado en el "de suyo» reinterpretando la comprensión de sentido desde la impresión de realidad; lo cual supondría adoptar la perspectiva de la consideración de qué sea el sentido desde su realidad física. Acaso con ello podría darse un pequeño paso para contribuir a aquella transformación de la hermenéutica que motivara el inicio de este trabajo. 
